\title{
The Driving Risk Analysis and Evaluation in Rightward Zone of Expressway Reconstruction and Extension Engineering
}

\author{
Chi Zhang $\mathbb{D}^{1,2,3}$ Bo Wang, ${ }^{1,2}$ Shaoxiang Yang, ${ }^{1,2}$ Min Zhang, \\ Quanli Gong, ${ }^{4}$ and Hong Zhang ${ }^{1,2}$ \\ ${ }^{1}$ Department of Highway, Chang'an University, Xi'an 710064, Shaanxi, China \\ ${ }^{2}$ Engineering Research Center of Highway Infrastructure Digitalization, Ministry of Education, Xi'an 710064, Shaanxi, China \\ ${ }^{3}$ China Communications Construction First Expressway Consultants Company Limited, Xi'an 710064, Shaanxi, China \\ ${ }^{4}$ Shenzhen Municipal Planning and Natural Resources Bureau, Shenzhen 518034, Guangdong, China
}

Correspondence should be addressed to Chi Zhang; zhangchi@chd.edu.cn

Received 28 November 2019; Revised 15 August 2020; Accepted 27 August 2020; Published 8 September 2020

Academic Editor: Eneko Osaba

Copyright ( $\odot 2020$ Chi Zhang et al. This is an open access article distributed under the Creative Commons Attribution License, which permits unrestricted use, distribution, and reproduction in any medium, provided the original work is properly cited.

In the expressway reconstruction and expansion engineering, the form of rightward zone is increasingly adopted, and its complicated traffic conditions can easily cause traffic accidents. In order to quickly and effectively grasp the traffic risk of the right diversion section, this study employs average speed, the coefficient of variation, the equivalent minimum safety distance, and the deceleration as evaluation indexes of driving risk, and then analyses the influence rules of traffic volume, the proportion of large vehicles, and the length of the transition section on each evaluation index by using Vissim simulation software. On the basis of this, we determine the weight of each evaluation index by the entropy method and establish the driving risk index evaluation model of the work zone with multiple linear regression. The results show that the partial regression coefficients of traffic volume, the proportion of large vehicles, and the length of the transition section to the driving risk index are $0.059,0.317$, and 0.15 , respectively. Finally, in this paper, we analyze the traffic risk of example section based on the driving risk evaluation model. The results of evaluation are consistent with the number of measured conflicts. This study proposes a new method for predicting the traffic risk of the expressway reconstruction and extension engineering, which can provide a reference for the development of safety management measures in the rightward zone.

\section{Introduction}

With the rapid development of the economy and the society, the capacity of expressway built in the early stage is gradually unable to meet the actual traffic demand. In the work zone of reconstruction and extension engineering, traffic vehicles, construction vehicles, and personnel are intertwined. The condition of the vehicle traffic is complex. Acceleration and deceleration, change of lanes, and other reactions frequently occur, leading to traffic accidents easily. According to relevant statistics [1], the accident rate in the work zone is much higher than that in normal road sections. From 2010 to 2014, in the United States, more than 4,400 people died in traffic accidents in the work zone and more than 200,000 people were injured in these accidents.
At present, there are a large number of four-lane expressway reconstruction and expansion engineering. In order to ensure the normal operation of traffic and to reduce the adverse impact on economic development during the period of the construction, the method of diversion to the right is adopted in many reconstruction and expansion engineering to ensure four lanes pass [2, 3]. Most of the research on traffic risks in the work zone is based on the partially closed and semienclosed working zone of expressway sections [4]. There are poor research and analysis on the rightward zone of expressway reconstruction and extension engineering.

To this end, we selected the rightward zone of expressway reconstruction and extension engineering as the research object and tried to establish a new work-zone traffic 
risk assessment model to help managers formulate a reasonable and effective management plan to reduce the traffic risk in the work zone.

\section{Literature Review}

In order to effectively carry out the research on the traffic risk of the rightward zone of expressway reconstruction and extension engineering, the following will review and summarize the previous research results from several aspects including research direction, risk types, risk mechanisms, and risk influencing factors.

Over the years, scholars from various countries have conducted much research on the risk of driving in the expressway work zone and have obtained a lot of research results. The current research is mainly divided into three aspects. Firstly, they analyzed the characteristics (e.g., crash severity, crash rate, and crash types) of the historic accident data and established the risk prediction model [5-8]. Secondly, they carried out a risk assessment based on the theory of traffic conflicts using the nonaccident data (e.g., the time to collision and deceleration rate to avoid the crash) [9-12]. In addition to the above two dominating research directions, some researchers have carried out related research from the perspective of psychology and physiology (e.g., speed preference and driver perception) [13-15].

In terms of traffic risk types in work zone, most scholars believe that rear-end collision risk in a car-following state is the most important type of risk $[16,17]$. Daniel et al. found that the main types of accidents in the work zone are rearend crashes, angle crashes, head-on crashes, and fixed object crashes [18].Garber and Zhao analyzed the characteristics of work-zone crashes that occurred in Virginia from 1996 through 1999, the results showed that rear-end crashes are the predominant crash type, and sideswipe-in-same-direction crashes mainly occurred in the transition section [19]. Li and Bai, after counting the fatal and injury accidents between 1992 and 2004 in Kansas highway work zones, found that the rear-end was the dominant injury accident type and head-on was the dominant type for fatal accidents [20].

In terms of factors affecting traffic safety in work zone, previous studies have shown that traffic risks are affected by various factors such as drivers, work zone, traffic volume, vehicle speed, and weather $[21,22]$. Indicators such as vehicle speed, traffic volume, vehicle model ratio, and the length of working zone can be effectively monitored and applied to risk analysis [23, 24]. Morgan et al. studied the relationship between the length of the transition section in the work zone and the driving risk, of which the results showed that the reduction of the transition section length will increase the driving risk to a certain extent [25]. Ge et al. used the VISSIM simulation model and the surrogate safety assessment model (SSAM) to analyze the relationship between the length of the warning zone and traffic conflicts, which showed that the traffic conflicts decreased as the length of the warning zone increased [26]. Ge et al. analyzed the impact of speed dispersion on traffic risk based on the improved time to collision (TTC) model, and the results showed that reducing speed dispersion can effectively reduce driving risk in work zone [27]. Yang et al. used the variable speed limit (VSL) system to verify that the dispersion of vehicle speed in the work zone is reduced, which can effectively improve road safety [28]. Meng et al. comprehensively considered the impact of traffic volume, vehicle model ratio, average speed, and other factors on traffic risks and established a novel probabilistic quantitative risk assessment (QRA) model [29]. Qu et al. analyzed the relationship between traffic states and conflicts, and the results showed that traffic volume, speed, and density are closely related to traffic risk [30].

In addition, there are two main methods for assessing traffic risks in the work zone. On the one hand, macrotraffic risk analysis, using indicators including vehicle speed discrete index, section speed change indicator, and running speed index, is conducted to analyze the significance and difference of the vehicle speed change $[31,32]$. On the other hand, microrisk analysis mainly uses the theory of traffic conflicts to predict the possibility of traffic conflicts $[33,34]$.

Since the rightward zone is different from the general work zone, many conclusions cannot be directly used. So, this paper will combine the characteristics of the rightward zone to comprehensively analyze the impact of traffic flow conditions and traffic organization indicators on the traffic operation of the work zone. Finally, we proposed a traffic risk assessment model for the rightward zone of the expressway from the macro- and microperspectives, and applied the assessment model to analyze and verify the sample road sections.

\section{Driving Risk of Rightward Zone}

3.1. The Form of Rightward Zone. In order to ensure the regular operation of traffic and reduce the adverse impact on economic development during the reconstruction and extension of some four-lane expressways widened into eight lanes, much proprietor selects the plan, which guarantees the smooth flow of four lanes during the construction period [35]. In order to maintain four-lane traffic flow, vehicles need to occupancy opposite lanes during the construction phase of subgrade and pavement. In the opposite lane, since it is necessary to separate two lanes for the opposite vehicle, the vehicle must be diverted rightwards to the two lanes widened to the outside before the vehicle enters the work zone, which is defined as a rightward zone. The section is in the form of a filled region, as shown in Figure 1, wherein the section in which redirects the vehicle to the right to complete the traffic conversion is defined as a rightward zone transition section, referred to as a transition section, in the form of a blue-filled region in Figure 1.

3.2. Analysis of Driving Risk. The road environment of the rightward zone is complicated. The alignment is changeable, the driving route is continuously changing, and construction compresses the driving space of the vehicle. Traffic information within the road range is abundant and miscellaneous, the driver operates the vehicle frequently, and the increased intensity of tension, to a certain extent, leads to a 


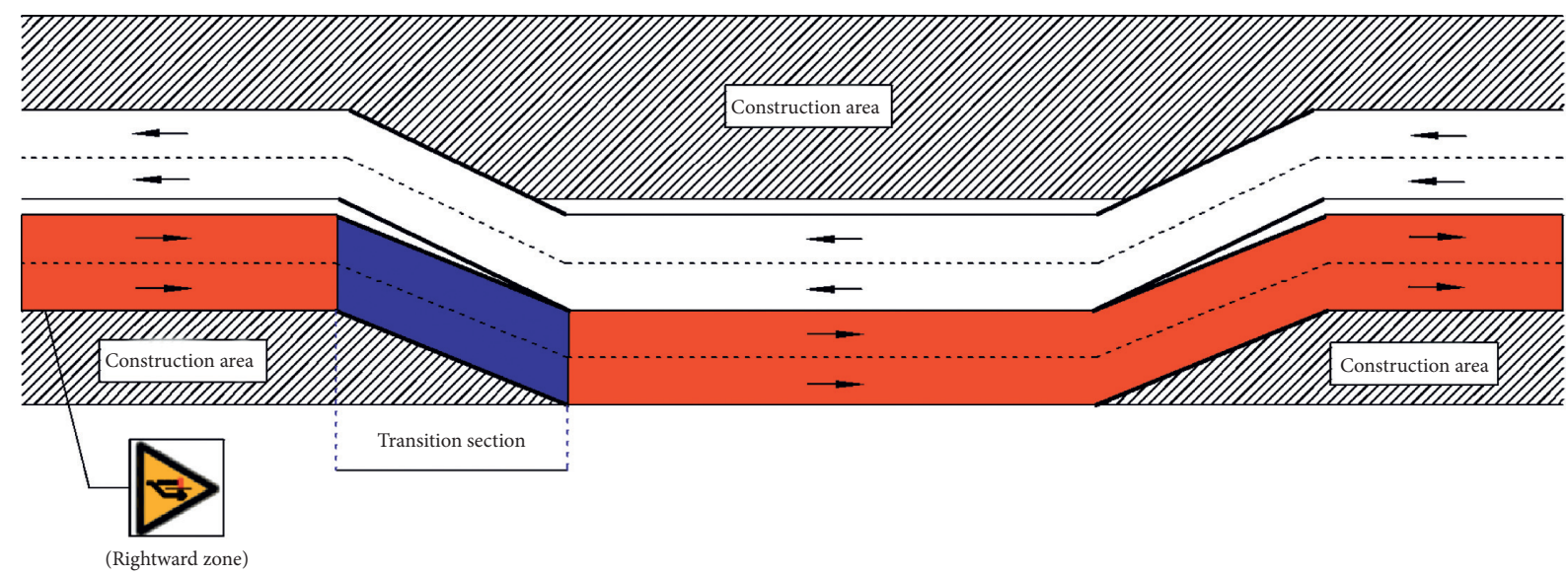

Figure 1: Work zone of the rightward zone.

higher risk of driving in the rightward zone. Besides, because there are two available lanes in the rightward zone, and the driver has strong adaptability to the rightward zone, the vehicles in the rightward zone drive at high speed, often exceeding the limit speed by a large proportion. On the whole, the traffic risk of vehicles in the rightward zone is higher than that of the typical expressway section.

The traffic system of a rightward zone is a dynamic system composed of humans, vehicles, roads, and the environment. Any change of each variable involved in it will have an impact on the operation of the entire traffic flow. We focus on the impact of traffic volume, traffic composition, and length of the transition section on the traffic safety of the rightward zone. We select traffic volume, traffic composition, and length of the transition section as dynamic influencing factors and analyze from the macro- and microperspectives.

3.2.1. Macroindicator. Macroscopically, we analyze the speed of the work zone through the average speed and coefficient of variation. Based on this, we carry out quantitative research from speed dispersion and significance of speed difference and analyze the macrorisk qualitative analysis on the rightward zone.

According to the relevant research [36], the higher the vehicle speed, the higher the accident rate and severity of the vehicle. For every $1 \mathrm{~km} / \mathrm{h}$ increase in the average speed, the traffic accident damage will increase by $3 \%$, and the deadly traffic accident will increase by $4 \% \sim 5 \%$. On the one hand, when the traffic system is in an unexpected situation, the time for the driver to observe and the judge is reduced, so the possibility of misjudgment and wrong decision-making in the operation of the vehicle as well as traffic accident rate will increase accordingly. On the other hand, as the speed of the car increases, the braking distance of the car increases, the turning radius becomes more substantial, and the lateral stability of the car decreases. When the driver slows in reacting or mishandles, it is easy to cause the vehicle to lose control and cause an accident [37].

The coefficient of variation is the ratio of the standard deviation of the vehicle speed to the average vehicle speed, and its magnitude reflects the degree of dispersion of the vehicle speed. The effect of speed discrepancies on traffic safety is essential that the traffic flow deviates from the steady-state due to the dispersion of the vehicle speed. The headway distance and spacing cannot be kept stable, the comfort level of the driver and passenger is reduced, the operating efficiency is reduced, and the probability of traffic accidents increases [38].

3.2.2. Microindicator. Microscopically, we analyze the correlation between the microevaluation index and the driving risk in the rightward zone according to the braking deceleration and the equivalent minimum safety distance.

Minimum safety distance equation is an indicator which takes into account the two factors of vehicle spacing and speed difference before and after. The expression is as shown in equation (1). MSDE decreases with the decrease of the headway $h$ distance, the decrease of the front vehicle speed, and the increase of the rear vehicle speed; when MSDE $>0$, it represents that the distance between the two vehicles is safe; when $\mathrm{MSDE} \leq 0$, it represents a potential danger between the two cars, and the greater the absolute value of the negative MSDE, the greater the risk of accidents [39]:

$$
\begin{aligned}
\operatorname{MSDE} & =1.47\left(V_{L} \times h-V_{F} \times \mathrm{PRT}\right)+\frac{V_{L}^{2}-V_{F}^{2}}{30(f \pm g)} \\
\operatorname{PRT} & =t_{1}+t_{2}+t_{3} .
\end{aligned}
$$

Here, $V_{L}$ is the front vehicle speed (mph); $V_{F}$ is the rear vehicle speed (mph); $h$ is the headway (s); PRT is the vehicle safety time (s); $f$ is the road friction coefficient; $g$ is the road longitudinal slope; $t_{1}$ is the reaction time of rear vehicle driver perceives; $t_{2}$ is the duration after the driver's foot leaves the brake until the brake has an effect; and $t_{3}$ is the duration of vehicle brake operation.

The deceleration of the braking process directly affects the driving safety of the vehicle, and its size and distribution reflect the emergency of the vehicle braking. When the deceleration is more significant than $3 \mathrm{~m} / \mathrm{s}^{2}$, the driver's vision is blurred, which seriously affects the safe driving of 
the vehicle. As the deceleration gradually increases, the driver's adverse reactions increase sharply, and the risk of traffic accidents increases [40].

Based on using indexes such as average speed, coefficient of variation, braking deceleration speed, and minimum safe distance equivalent to represent the driving risk, the driving risk index is further defined to evaluate the driving risk of the rightward zone comprehensively (as shown in Figure 2). The driving risk index is a weighted sum of the driving risk evaluation indexes of the rightward zone to obtain the driving risk index value used to reflect the driving risk degree of the rightward zone. The higher the driving risk index is, the higher the driving risk of the vehicle in this section is, moreover, vice versa.

\section{Data Collection}

4.1. Establishment of a Simulated Road Section. Existing studies have proved that Vissim simulation software can accurately and effectively simulate and predict the state of traffic flow [41, 42]. According to the running characteristics of vehicles in an expressway work zone, we applied Vissim simulation software to simulate the running state of traffic flow in the rightward zone of the expressway reconstruction and extension engineering. According to the actual traffic condition of the right-turning lane diversion section, the establishment of the simulation model is the basis of traffic simulation. Select the work zone of an expressway in which the number of lanes has increased from four to eight in Anhui Province as the investigation section. Based on the work zone of a rightward zone in the reconstruction and extension engineering section, investigate the traffic data and establish the simulation model. Design the work zone of this rightward zone with a speed of $120 \mathrm{~km} / \mathrm{h}$, double side widening, lane width of $3.75 \mathrm{~m}$, and transition section length of $60 \mathrm{~m}$. The length of the other sections is shown in Table 1.

4.2. Simulation Strategy. The traffic volume $(Q)$, the proportion of the large vehicles $(P)$, and the length of transition section $(L)$ are selected to analyze the driving risk of the rightward zone. By setting the detector, the simulation data are collected to observe the running condition of vehicles under different traffic flow conditions. After processing the data including speed, acceleration, arrival time, and other original data of each car which passes through the detector section, we calculate the average speed (AS), coefficient of variation (CV) [43], minimum safe distance equivalent (MSDE) [44], and deceleration (a), respectively. Furthermore, the changes of evaluation indexes under different traffic conditions are analyzed to explore the internal influence rules of traffic volume, the proportion of large vehicles, and the change of transition section length on vehicles driving in the rightward zone.

Table 2 shows the simulation experiment design. Figure 3 shows the layout of detection points. Figures 4-6 show the analysis of the influencing factors under the separate changes of the three factors of the traffic volume, the proportion of the large vehicles, the length of transition section. Figure 7 presents the distribution and change of braking deceleration in the rightward zone.

\subsection{Analysis of Influencing Factors}

4.3.1. Average Speed. Through the analysis of Figures 4(a) and 4(b), it can be found that as the traffic volume and the proportion of large vehicles increase, the average speed decreases, which indicates that the average speed is negatively correlated with the traffic volume and the proportion of large vehicles. It can be seen from Figure 4(c) that, as the length of the transition section increases, the average speed increases, indicating that the average speed is positively correlated with the length of the transition section. It is worth noting that the average speed increases significantly with the increase of the length of the transition section within a specific range. When the length of the transition section increases to a specific value, the change range of the average speed with the increase of the length of the transition section is small and tends to be approximately stable. By observing the lateral variation trend of each figure in Figure 4, it can be found that the variation trend of the average speed is approximately the same, which decreases firstly and then rises. The difference is that the various points of the trend will gradually move forward with the increase of traffic volume, gradually move backward with the increase of the length of transition section, and remain unchanged with the increase of the large vehicles' proportion.

4.3.2. Coefficient of Variation. From Figure 5, compared with other sections, the coefficient of variation of the section before and after the transition section is more significant, reaching 0.66 , while that of other sections is slightly larger than 0.1. From Figure 5(a), the coefficient of variation is positively correlated with the traffic volume. As the traffic volume increases, the coefficient of variation increases gradually. From Figure 5(b), with the increase of the proportion of large vehicles, the coefficient of variation in the range before and after the transition section will increase significantly. From Figure 5(c), within a specific range, coefficient of variation is negatively correlated with the length of the transition section. As the length of the transition section increases, the coefficient of variation of each section before and after the transition section decreases gradually but tends to be stable when it increases to a certain length.

4.3.3. Minimum Safe Distance Equivalent. As can be seen from the figures in Figure 6, the minimum safe distance equivalent is negatively correlated with the traffic volume and the proportion of large vehicles. With the increase of the traffic volume and the proportion of large vehicles, the minimum safe distance equivalent keeps decreasing, indicating that the driving risk is increasing; however, the minimum safe distance equivalent presents different variation trends with the change of transition section length at 


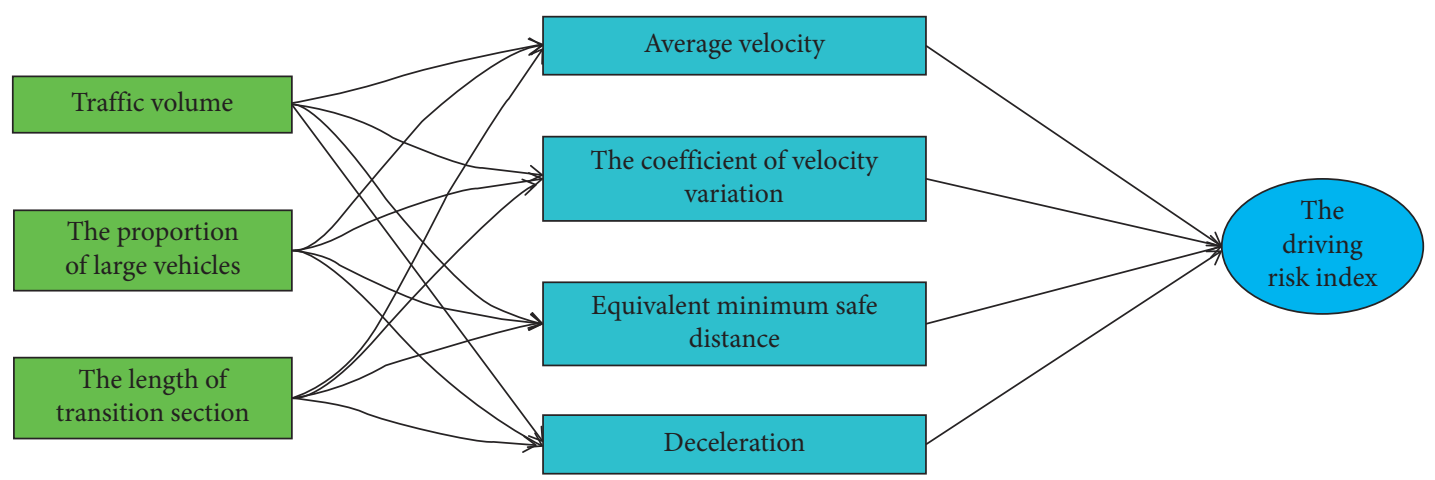

FIGURE 2: Schematic diagram of traffic risk analysis for rightward zone.

TABLE 1: Length of each section of the work zone.

\begin{tabular}{lcccccc}
\hline Section & Warning zone & Upstream transition zone & Buffer zone & Working zone & Downstream transition zone & Termination zone \\
\hline Length $(\mathrm{m})$ & 1600 & 90 & 50 & 2100 & 30 & 30
\end{tabular}

TABle 2: Simulation experiment design.

\begin{tabular}{|c|c|c|c|c|c|}
\hline Group & Research purposes & $Q[\mathrm{veh} / \mathrm{h}]$ & $P$ & $L(\mathrm{~m})$ & $\begin{array}{l}\text { Evaluation } \\
\text { indexes }\end{array}$ \\
\hline 1 & $\begin{array}{l}\text { The impact of traffic volume on traffic } \\
\text { risk }\end{array}$ & $\begin{array}{l}800,1000,1200,1400,1600 \\
1800,2000,2200,2400\end{array}$ & $40 \%$ & 100 & $A S, C V, \mathrm{MSDE}$ \\
\hline 2 & $\begin{array}{l}\text { The impact of the proportion of large } \\
\text { vehicles on traffic risk }\end{array}$ & 1800 & $\begin{array}{l}20 \%, 30 \% \\
40 \%, 50 \%\end{array}$ & 100 & $A S, C V, \mathrm{MSDE}$ \\
\hline 3 & $\begin{array}{l}\text { The impact of the length of transition } \\
\text { section on traffic risk }\end{array}$ & 1800 & $40 \%$ & $\begin{array}{c}20,40,60,80,100 \\
120,140,160\end{array}$ & $A S, C V, \mathrm{MSDE}$ \\
\hline 4 & $\begin{array}{l}\text { The distribution and change of braking } \\
\text { deceleration }\end{array}$ & 1800 & $40 \%$ & 100 & $a$ \\
\hline
\end{tabular}

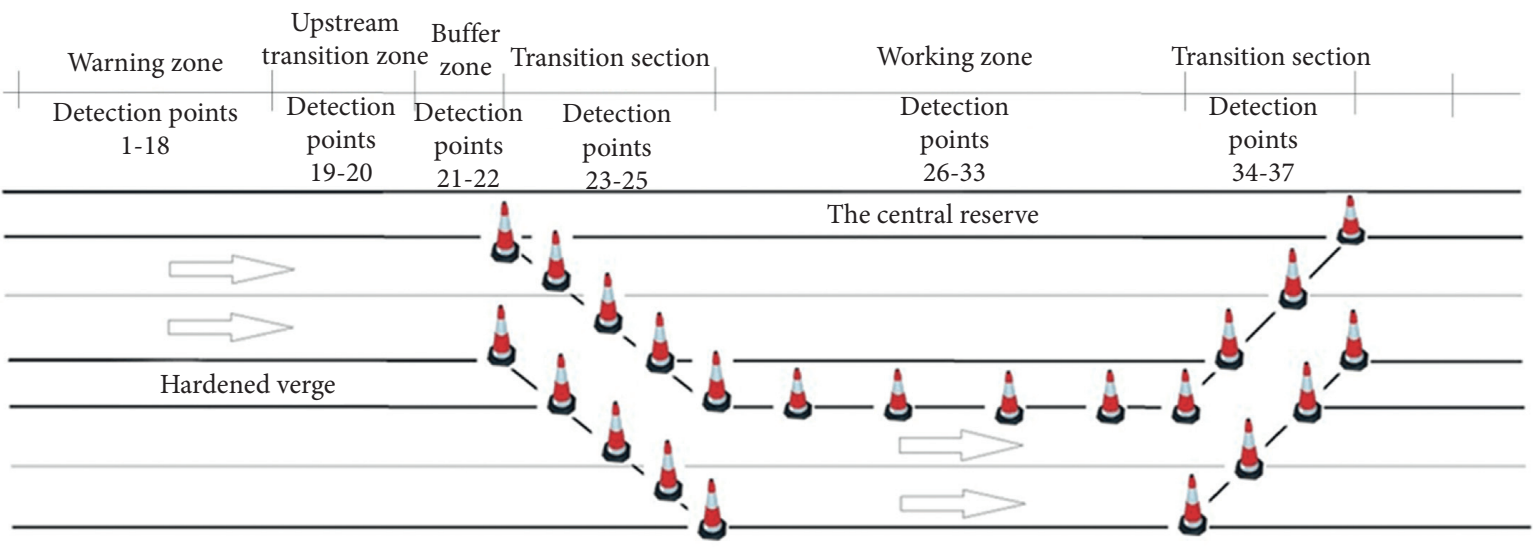

Figure 3: The layout of data detection points.

different sections. For each section in front of the transition section, the minimum safe distance equivalent increases firstly with the length of the transition section and then tends to be stable. For each section after the transition section, MSDE is more significant when the length of the transition section $(20 \mathrm{~m}$ and $40 \mathrm{~m})$ is small. The possible reason is that relatively few vehicles pass through the transition section and enter the working zone due to the severe congestion before the transition section.
4.3.4. Deceleration. Figure 7 shows that the deceleration value in this case mainly focuses on $0.3 \mathrm{~m} / \mathrm{s}^{2}-2.3 \mathrm{~m} / \mathrm{s}^{2}$, especially $0.3 \mathrm{~m} / \mathrm{s}^{2}$, and the rest of the deceleration value is scattered in the range of $2.3 \mathrm{~m} / \mathrm{s}^{2}-7.5 \mathrm{~m} / \mathrm{s}^{2}$, and the prominent part is around $2.9 \mathrm{~m} / \mathrm{s}^{2}$. In the rightward zone of the work zone, the braking speed of some vehicles is above $5 \mathrm{~m} / \mathrm{s}^{2}$, and this is because the emergency braking of vehicles requires greater deceleration to avoid collisions, which leads to greater driving risks. 


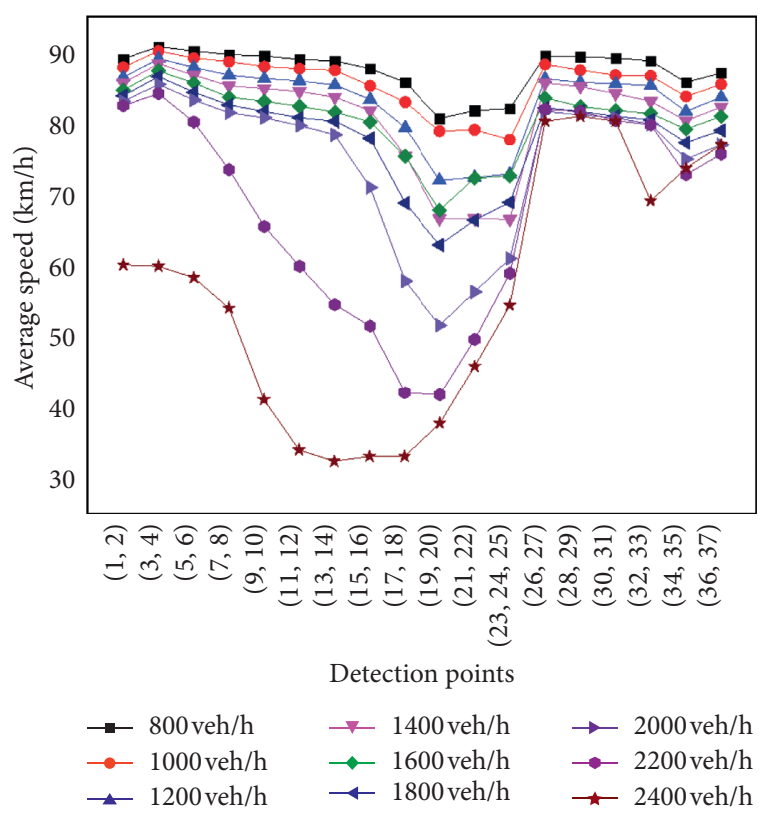

(a)

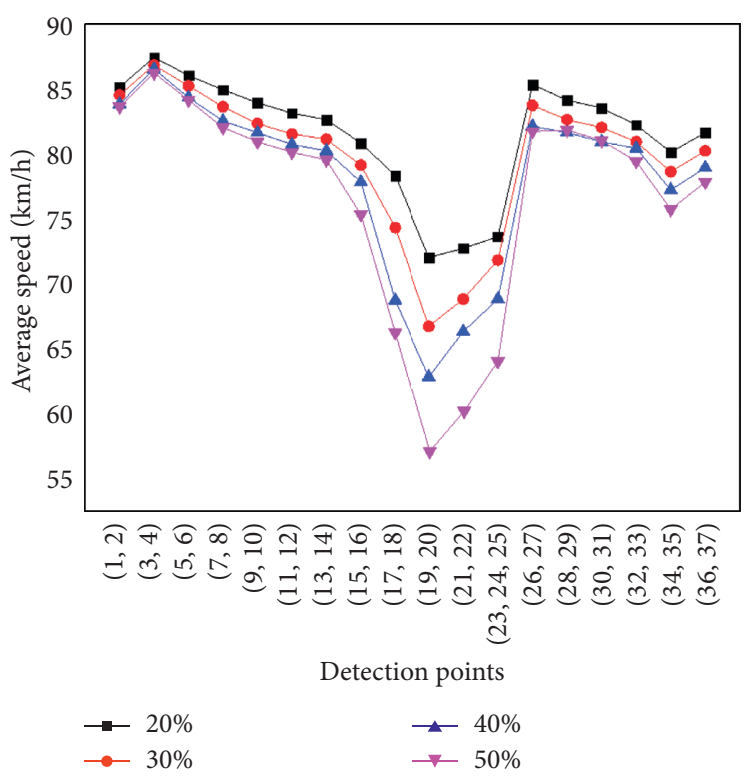

(b)

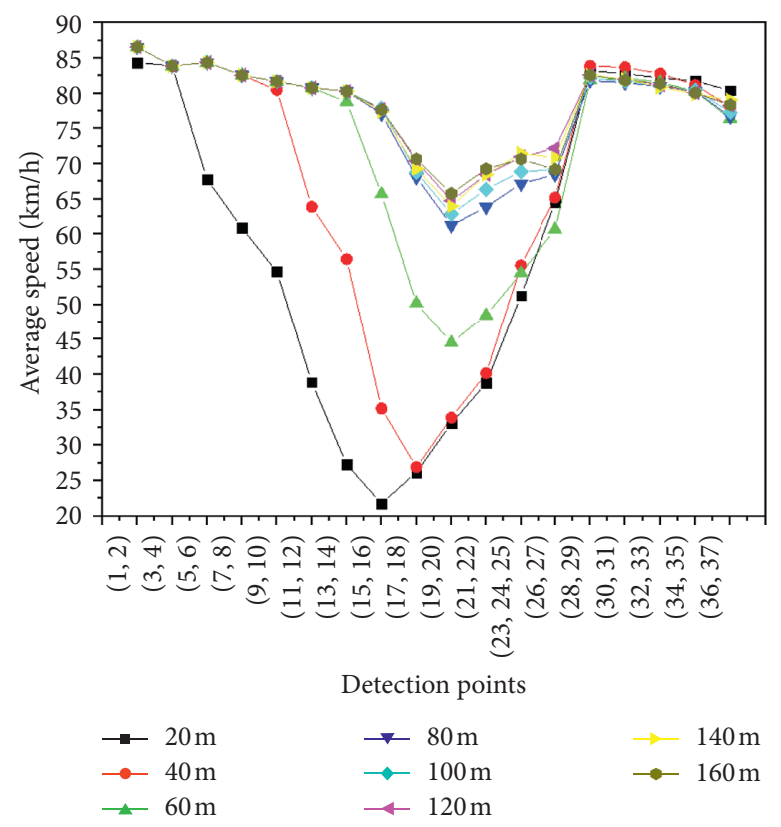

(c)

Figure 4: Average speed varies with each factor. (a) Average speed varies with traffic volume. (b) Average speed varies with the proportion of large vehicles. (c) Average speed varies with the length of the transition section.

\section{Establishment of Driving Risk Evaluation Model}

We define the driving risk index to represent the driving safety level of the rightward zone of expressway reconstruction and extension engineering. We apply the entropy value method to determine the weight of average speed, coefficient of variation, minimum safe distance equivalent, and deceleration, and calculate the driving risk index value by weighting. Because the average speed and coefficient of variation are macroindicators, the speed data of the work zone can be adopted directly. Since the minimum safe distance equivalent and deceleration are the indicators of a specific vehicle, we select the representative 85 th percentile data as the representative, that is, $a_{85}$ and $\mathrm{MSDE}_{85}$.

5.1. Introduction to Entropy Method. The entropy method is a mathematical method used to judge the dispersion degree of an index. The higher the degree of dispersion, the higher the influence of this index on a comprehensive 


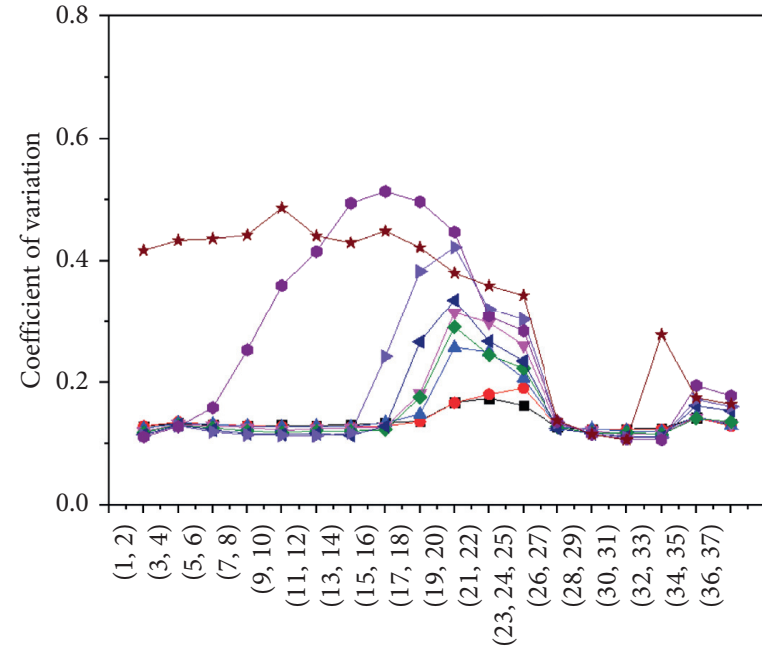

Detection points

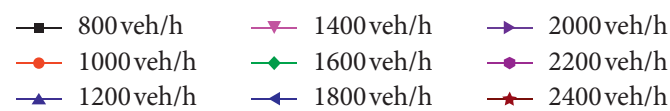

(a)

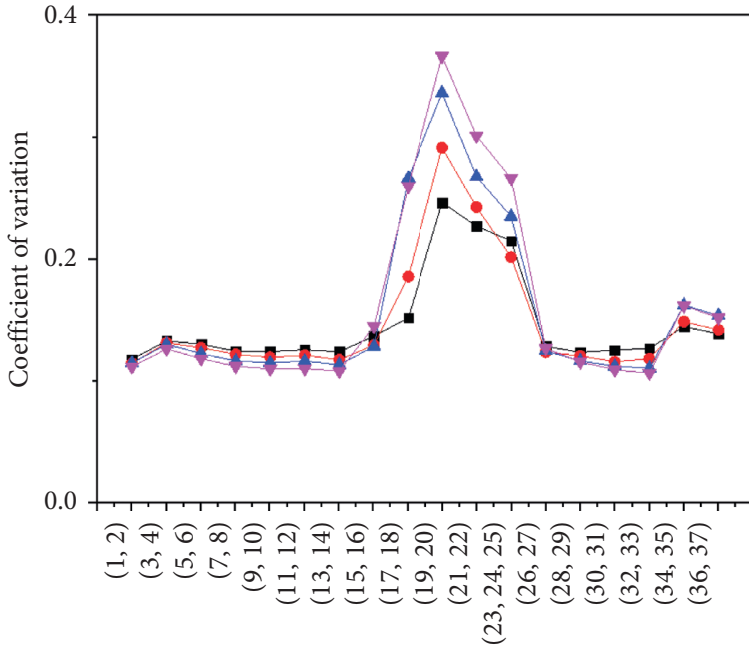

Detection points

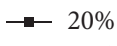

$\rightarrow 40 \%$

(b)

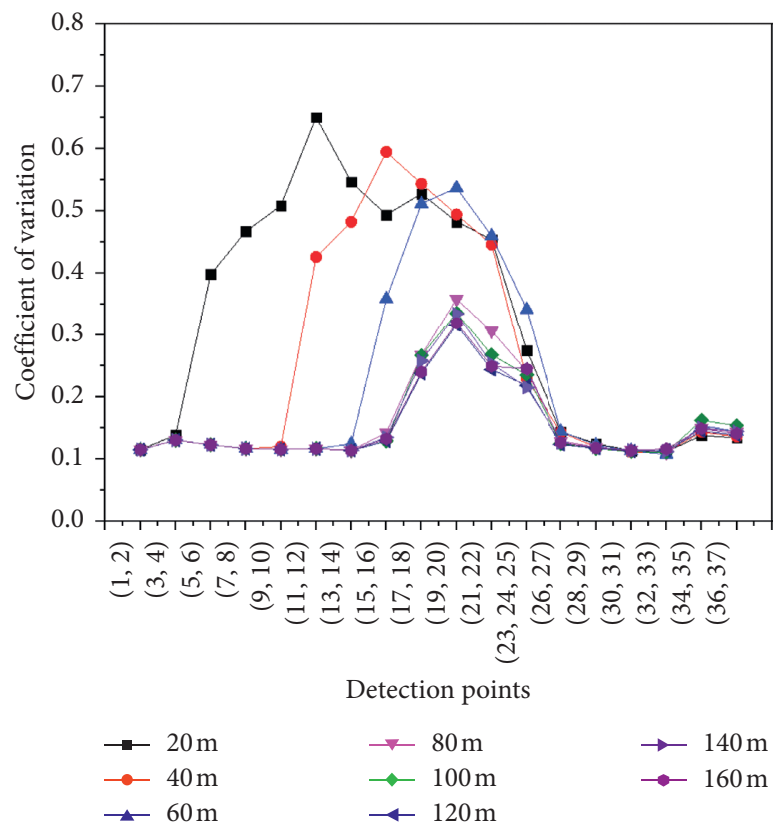

(c)

Figure 5: Coefficient of variation varies with each factor. (a) Coefficient of variation varies with traffic volume. (b) Coefficient of variation varies with the proportion of large vehicles. (c) Coefficient of variation varies with the length of the transition section.

evaluation [45]. The calculation steps of the entropy method are as follows:

(a) Unified treatment of indicators:

Let the original evaluation matrix be $X=\left(x_{i j}\right)_{m \times n}$. Since the benchmark and measurement unit of each evaluation index is different, the four indexes are normalized before comprehensive calculation. The specific methods are as follows:

Forward indicator:

$$
3 x_{i j}^{\prime}=\frac{x_{i j}-\min \left\{x_{1 j}, x_{2 j}, \ldots, x_{n j}\right\}}{\max \left\{x_{1 j}, x_{2 j}, \ldots, x_{n j}\right\}-\min \left\{x_{1 j}, x_{2 j}, \ldots, x_{n j}\right\}} .
$$

Backward indicator:

$$
x_{i j}^{\prime}=\frac{\max \left\{x_{1 j}, x_{2 j}, \ldots, x_{n j}\right\}-x_{i j}}{\max \left\{x_{1 j}, x_{2 j}, \ldots, x_{n j}\right\}-\min \left\{x_{1 j}, x_{2 j}, \ldots, x_{n j}\right\}} .
$$




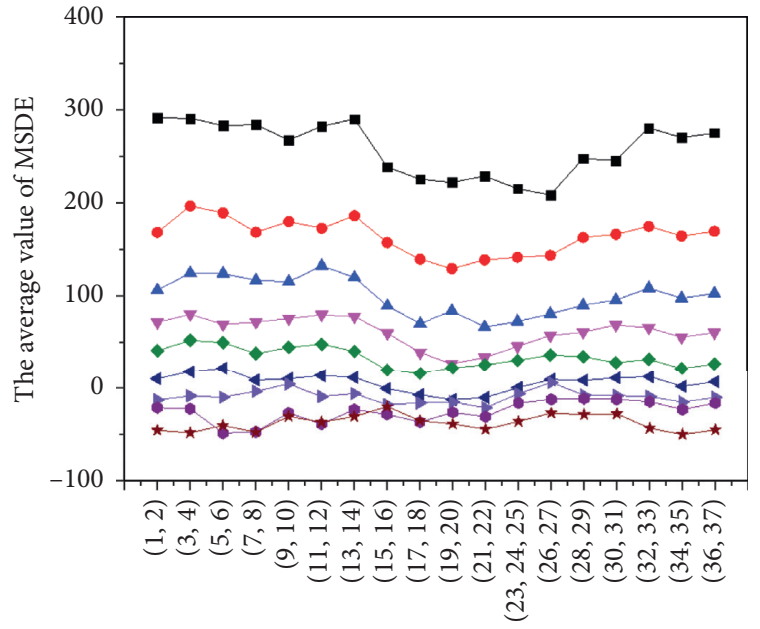

Detection points

- $800 \mathrm{veh} / \mathrm{h}$

$\rightarrow 1000 \mathrm{veh} / \mathrm{h}$

$\rightarrow 1200 \mathrm{veh} / \mathrm{h}$

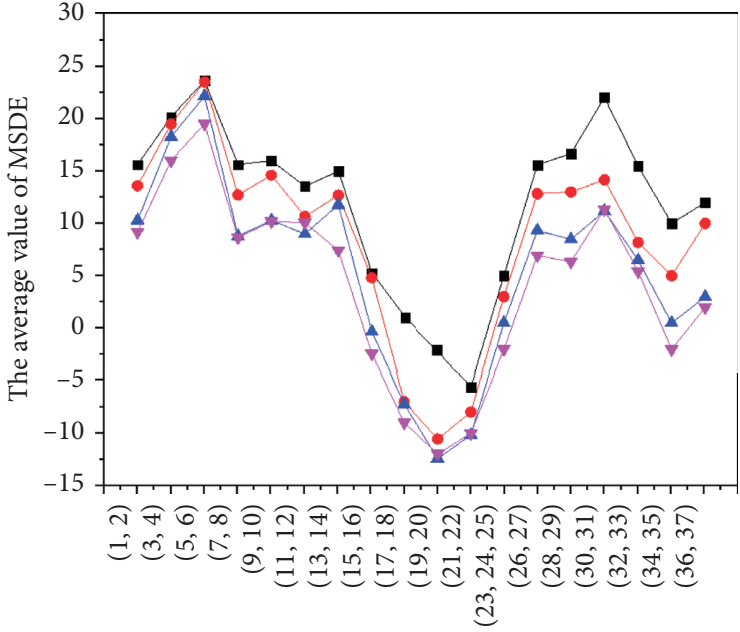

Detection points

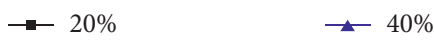

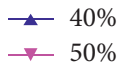

(a)

(b)

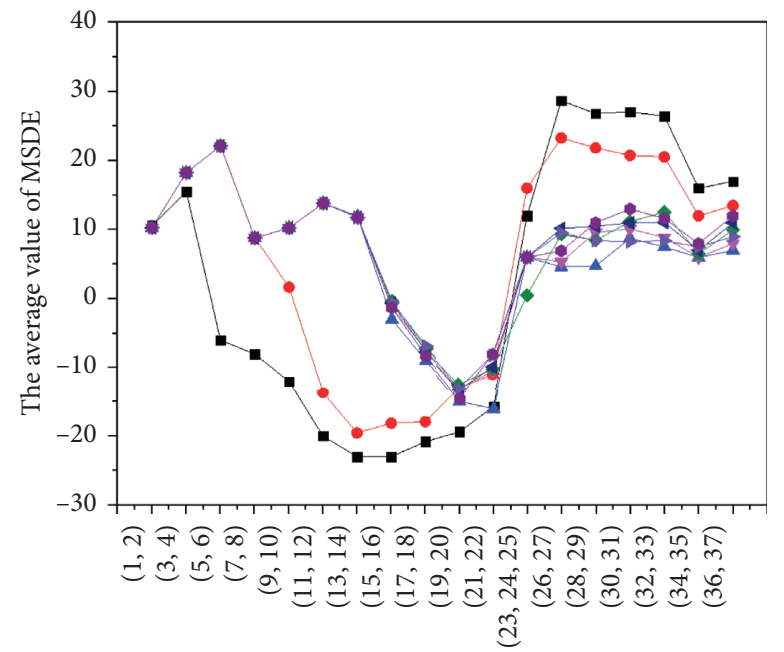

Detection points

\begin{tabular}{|c|c|}
\hline$\rightarrow 20 \mathrm{~m}$ & $\rightarrow 80 \mathrm{~m}$ \\
\hline $\begin{array}{l}\longrightarrow 40 \mathrm{~m} \\
\leftarrow \quad 60 \mathrm{~m}\end{array}$ & $\begin{array}{l}\rightarrow 100 \mathrm{~m} \\
\longleftarrow 120 \mathrm{~m}\end{array}$ \\
\hline
\end{tabular}

(c)

Figure 6: The minimum safe distance equivalent varies with each factor. (a) The average value of MSDE varies with traffic volume. (b) The value of MSDE varies with the proportion of large vehicles. (c) The average value of MSDE varies with the length of the transition section.

Then, $x_{i j}^{\prime}$ is the value of the $j$ th index belong to the ith evaluated unit $(i=1,2, \ldots, n ; j=1,2, \ldots, m)$. For convenience, $x_{i j}^{\prime}$ remains $x_{i j}^{\prime}$ after normalization.

(b) Calculate the proportion of the ith evaluation unit in the $j$ th index:

$$
p_{i j}=\frac{x_{i j}}{\sum_{i=1}^{n} x_{i j}}, \quad i=1, \ldots, n j=1, \ldots, m .
$$

(c) Calculate the entropy value of the jth index:

$$
e_{j}=-k \sum_{i=1}^{n} p_{i j} \ln \left(p_{i j}\right)
$$

Constant $k=\ln (m)$, to ensure $0 \leq e_{j} \leq 1$.

(d) Calculate redundancy of information entropy:

$$
d_{j}=1-e_{j}
$$

(e) Calculate the weight of each index: 


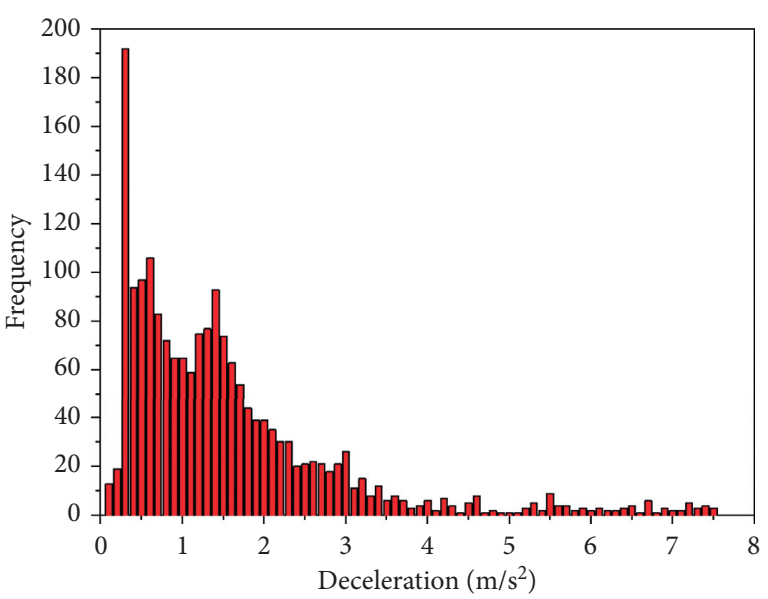

Figure 7: Deceleration frequency distribution.

$$
W_{j}=\frac{d_{j}}{\sum_{j=1}^{m} d_{j}}, \quad j=1, \ldots, m .
$$

(f) The weight of the jth index and the proportion of the ith sample of the jth index in the standardized matrix to the index $p_{i j}$ are taken as the evaluation value $S_{i j}$ of $x_{i j}$, and the comprehensive score of this sample is obtained by adding the $S_{i j}$ of the same sample:

$$
\begin{gathered}
S_{i j}=W_{j} * p_{i j}, \quad i=1, \ldots, n, \\
S_{i}=\sum_{j=1}^{m} S_{i j}, \quad i=1, \ldots, n .
\end{gathered}
$$

5.2. Evaluation Results of Driving Risk Index through Entropy Method. According to the above steps, Matlab software was used to compile programs to analyze the average speed, coefficient of variation, the minimum safe distance equivalent, and the deceleration, and obtain the entropy analysis results of the four indexes, as shown in Table 3.

Table 3 shows that the data of the coefficient of variation in the rightward zone of expressway reconstruction and extension engineering are the most orderly and contain the most information. Thus, the weight is the largest, followed by the average speed, deceleration speed, and equivalent minimum safety distance. According to the calculation results of $W_{j}$, we obtain the calculation formula of the driving risk index DR of the rightward zone as follows:

$$
\mathrm{DR}=0.1311 x_{1}+0.6354 x_{2}+0.1052 x_{3}+0.1283 x_{4} .
$$

In the formula, DR is the driving risk index; $x_{1}$ is the standardized value of average speed; $x_{2}$ is the standardized value of coefficient of variation; $x_{3}$ is the standardized value of equivalent minimum safety distance; and $x_{4}$ is the standardized value of deceleration.

5.3. Determination of the Classification Threshold of Driving Risk Index. Calculate the driving risk index of all samples according to equation (9). Since the driving risk index was a decimal between 0 and 1 , the driving risk index was expanded by 100 times to facilitate analysis and obtain the cumulative frequency distribution of the driving risk index, as shown in Figure 8.

According to the principle of statistics, take the corresponding values of $15 \%, 50 \%$, and $85 \%$ as grading thresholds, and divide the driving risk into four grades: safe, relatively safe, relatively dangerous, and dangerous. The results are shown in Table 4.

\subsection{Multiple Regression Evaluation Models of Driving Risk Index for Rightward Zone}

5.4.1. Modeling. Given the distribution characteristics of simulation test data and the feasibility of modeling, multiple linear regression models can be used to determine the relationship between driving risk index and driving risk influencing factors of the rightward zone. Take the traffic volume, the proportion of large vehicles, and the length of the transition section as independent variables, and take the driving risk index as the dependent variable:

$$
\mathrm{DR}=0.059 Q+0.317 P-0.15 L-5.841 .
$$

In the formula, $\mathrm{DR}$ is the driving risk index $(\times 100) ; \mathrm{Q}$ is the traffic volume $(\mathrm{veh} / \mathrm{h} / \mathrm{ln}) ; P$ is the proportion of large vehicles (\%); and $L$ is the length of the transition section.

5.4.2. Model Checking. Table 5 shows the fitting situation of the driving risk model of the rightward zone, with the multiple correlation coefficient of 0.935 and the judgment coefficient of 0.875 . According to the multiple correlation coefficient and judgment coefficient, the goodness of fit of driving risk model in operation area is higher.

Besides, the concomitant probability corresponding to the F statistic is 0 , less than 0.05 , and the linear relationship of the equation is significant. The joint probability of $t$ statistics of $Q, P$, and $L$ is 0 , less than 0.05 , suggesting that $Q$, $P, L$, and $D R$ have an apparent linear relationship. According to the regression coefficient of the model, the larger the traffic volume is, the higher the proportion of large vehicles is, the shorter the length of transition section is, and the higher the driving risk.

\section{Example Verification}

In order to further verify that the proposed risk evaluation model of the rightward zone in the expressway reconstruction and extension engineering in this article is practical and useful, in October 2018, after obtaining the consent of the $\mathrm{K}$ expressway management department, the research team went to Anhui Province to collect data in the work zone, and the site of the work zone is shown in Figure 9. Through proper processing of traffic data collected on this section, obtain indexes such as average speed, coefficient of variation, minimum safe distance equivalent, and deceleration. Finally, evaluate the driving risk of this section.

The section of the work zone is the four-lane expressway widened into the eight-lane project. The form of the work zone is the rightward zone, and the driving vehicle is 
TABLE 3: Calculation results of the entropy method.

\begin{tabular}{lcccc}
\hline Category & Average speed & Coefficient of variation & The minimum safe distance equivalent & Deceleration \\
\hline$e_{j}$ & 0.9771 & 0.8888 & 0.9816 & 0.9775 \\
$d_{j}$ & 0.0229 & 0.1112 & 0.0184 & 0.0225 \\
$W_{j}$ & 0.1311 & 0.6354 & 0.1052 & 0.1283 \\
\hline
\end{tabular}

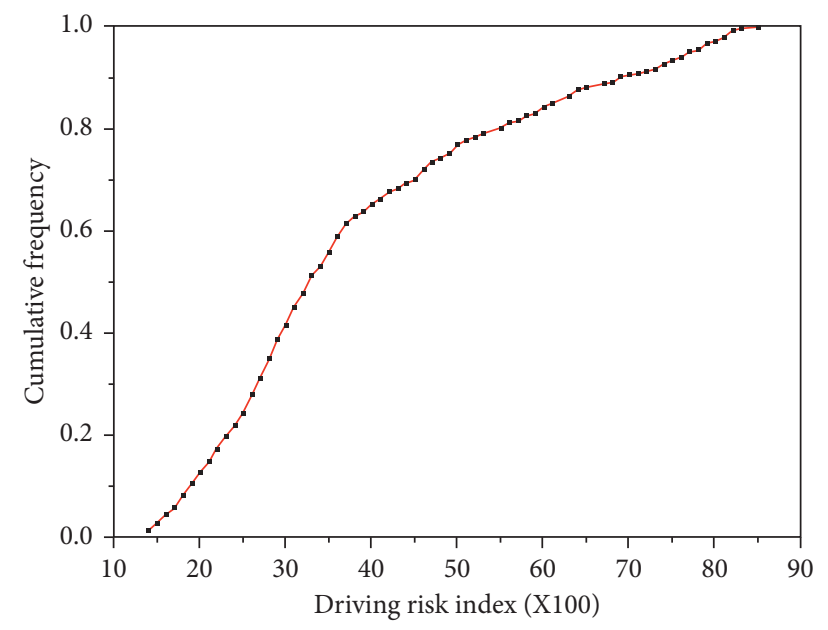

FIGURE 8: cumulative frequency distribution of the driving risk index.

TABle 4: Driving risk index division.

\begin{tabular}{lcccc}
\hline Grade & Safe & Relatively safe & Relatively dangerous & Dangerous \\
\hline Value range & $<22$ & $22-33$ & $33-61$ & $>61$ \\
\hline
\end{tabular}

TABLE 5: The goodness of fit test of the driving risk model.

\begin{tabular}{lccc}
\hline Multiple correlation coefficient $R$ & Judge coefficient $R^{2}$ & After adjustment $R^{2}$ & Standard deviation \\
\hline 0.935 & 0.875 & 0.874 & 6.488 \\
\hline
\end{tabular}

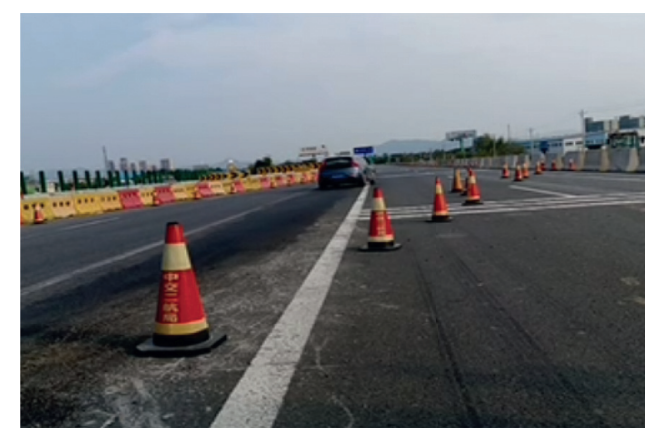

(a)

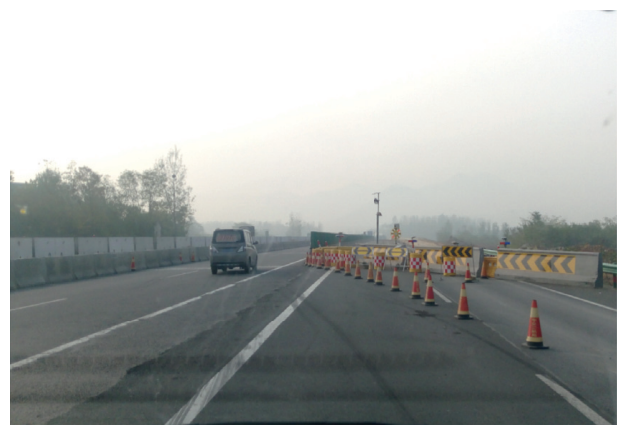

(b)

Figure 9: Scene photos of the work zone.

transferred to the right half of the road. Set up 8 typical cross section data collection points. Then, apply the chain Doppler radar speed measurement and camera to collect data. The location of the collection point is shown in Figure 10. Among them, the detection section No. 1 is located at the beginning of the warning zone; No. 2 is located at the warning zone, which is $400 \mathrm{~m}$ away from the start of the warning zone; No. 3 is located at the warning zone, which is $1000 \mathrm{~m}$ from the start of the warning zone; No. 4 is located at the beginning of the upstream transition section; No. 5 is at the beginning of the rightward zone transition section; No. 6 is located at the midpoint of the work zone; No. 7 is located at the beginning of the downstream transition section; and No. 8 is located at the end of the work zone. 


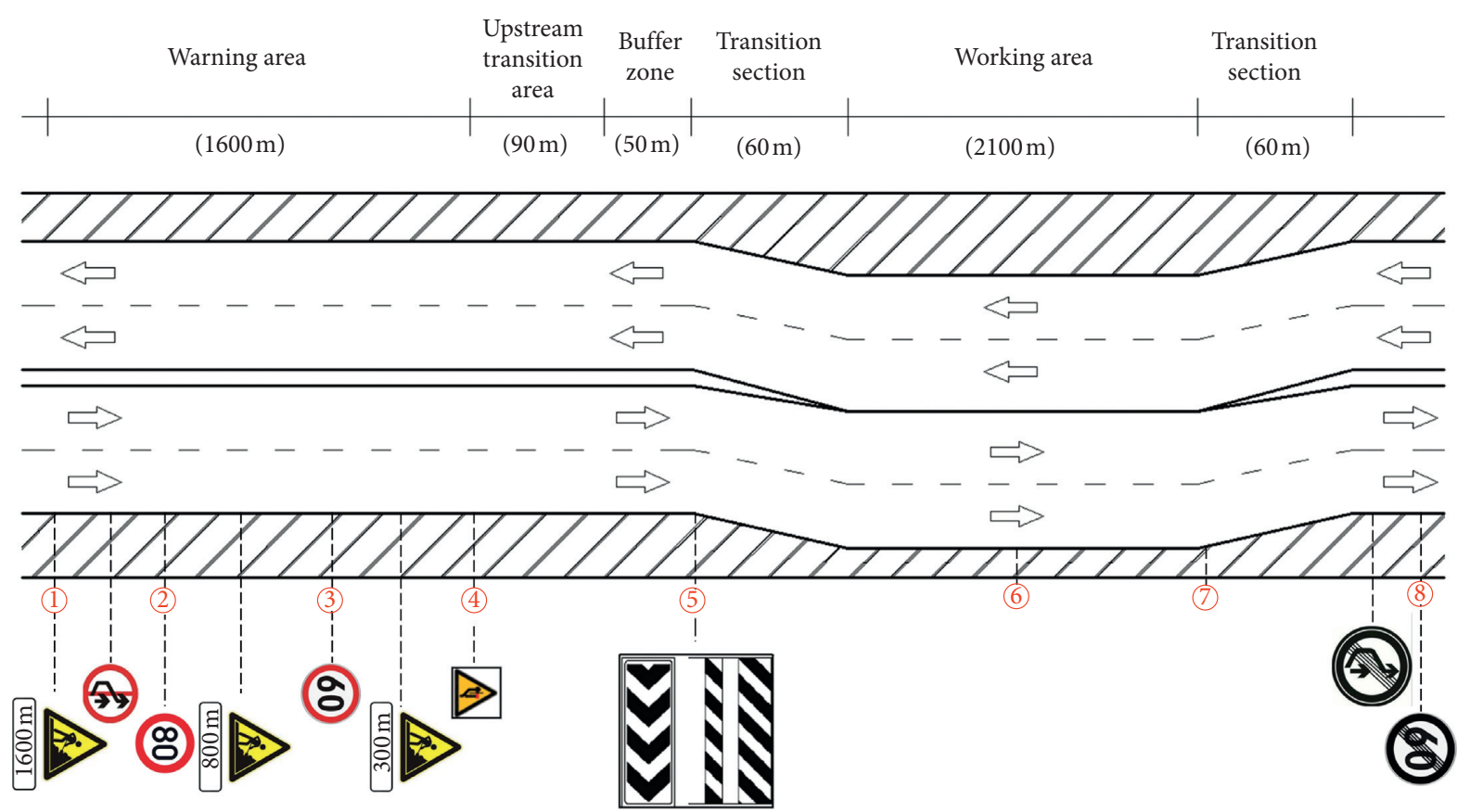

Figure 10: Collection point location.

TABLE 6: Driving risk assessment results of a case.

\begin{tabular}{lcccccc}
\hline Length of transition $(\mathrm{m})$ & $V$ & $\mathrm{CV}$ & $a_{85}$ & MSDE $_{85}$ & DR & Measured conflict \\
\hline 60 & 80.375 & 0.17 & 2.52 & 66.71 & 0.33 & 31 \\
100 & 80.729 & 0.15 & 1.89 & 69.29 & 0.27 & 18 \\
\hline
\end{tabular}

Set the length of the original transition section in the work zone of the rightward zone at $60 \mathrm{~m}$, which was increased to $100 \mathrm{~m}$ after optimization. Collect traffic data under the two conditions of one hour for comparative analysis. The driving risk evaluation results and the actual conflicts are shown in Table 6.

Table 6 shows that the driving risk index is consistent with the actual traffic conditions, indicating that the driving risk assessment results are reliable. Besides, the driving risk of the example section belongs to a safer category. By optimizing and increasing the length of the transition section, the driving risk decreases to some extent.

\section{Conclusions}

(1) This paper takes the driving risk of the rightward zone of expressway reconstruction and extension engineering as the research object. Micro and macro traffic flow parameters were selected to measure the driving risk index, which was taken as an index to indicate the driving risk. Simulate the traffic flow in the work zone by traffic simulation technology, the influence of traffic volume, the proportion of large vehicles, and the length of the transition section on each evaluation index were analyzed. Based on the entropy method, the relationship between the driving risk index and each evaluation index was determined. Furthermore, establish the multiple linear regression models of vehicle risk index, traffic volume, the proportion of large vehicles, and the length of the transition section.

(2) Traffic volume, the proportion of large vehicles, and the length of transition section all have influences on the driving risk of the rightward zone, among which the driving risk is positively correlated with traffic volume and the proportion of large vehicles, while negatively correlated with the length of the transition section.

(3) In this paper, the traffic risk evaluation model of the expressway reconstruction and extension engineering rightward zone is verified by the traffic data of a measured section in Anhui Province, which shows that the model is practical and useful.

(4) In this paper, study the traffic risk evaluation model of the expressway reconstruction and extension engineering in the form of four lanes widened into eight lanes. Only consider the traffic volume, the proportion of large vehicles, and the length of the transition section. In the next stage, we should consider more work-zone forms and influencing factors in the study of driving safety.

\section{Data Availability}

The data used to support the findings of this study are available from the corresponding author upon request. 


\section{Conflicts of Interest}

The authors declare that they have no conflicts of interest regarding the publication of this paper.

\section{Acknowledgments}

The authors appreciate National Key R\&D Program of China (no. 2017YFC0803906), Key Laboratory for Special Area Expressway Engineering of Ministry of Education for the financial support.

\section{References}

[1] Federal Highway Administration, Creating Safer Work Zones: Improving Operations on Both Sides of the Barrel, Federal Highway Administration, Washington, DC, USA, 2014, https://safety.fhwa.dot.gov/wz/resources/fhwasa03012/.

[2] City of Miramar, "Project 7: Homestead Extension FL Turnpike (HEFT) Widening," 2020, https://www.miramarfl. gov/393/FDOTBroward-County-Projects.

[3] XinKuai News, "Zhongjiang Expressway will be expanded from four lanes to eight lanes," 2020.http://ep.ycwb.com/ epaper/xkb/html/2020-07/03/content_315_285212.htm not a.

[4] H. Yang, K. Ozbay, O. Ozturk, and K. Xie, "Work zone safety analysis and modeling: a state-of-the-art review," Traffic Injury Prevention, vol. 16, no. 4, pp. 387-396, 2015.

[5] J. Weng, Q. Meng, and X. Yan, "Analysis of work zone rearend crash risk for different vehicle-following patterns," Accident Analysis \& Prevention, vol. 72, pp. 449-457, 2014.

[6] K. Koilada, A. S. Mane, S. S. Pulugurtha et al., "Odds of work zone crash occurrence and getting involved in advance warning, transition, and activity areas by injury severity," IATSS Research, vol. 44, no. 1, pp. 75-83, 2019.

[7] M. Yu, C. Zheng, and C. Ma, "Analysis of injury severity of rear-end crashes in work zones: a random parameters approach with heterogeneity in means and variances," Analytic Methods in Accident Research, vol. 27, Article ID 100126, 2020.

[8] K. Zhang, M. Hassan, M. Yahaya, and S. Yang, "Analysis of work-zone crashes using the ordered probit model with factor analysis in Egypt," Journal of Advanced Transportation, vol. 2018, Article ID 8570207, 10 pages, 2018.

[9] J. Weng, S. Xue, Y. Yang, X. Yan, and X. Qu, "In-depth analysis of drivers' merging behavior and rear-end crash risks in work zone merging areas," Accident Analysis \& Prevention, vol. 77, pp. 51-61, 2015.

[10] H. Ge, R. Xia, H. Sun, Y. Yang, and M. Huang, "Construction and simulation of rear-end conflicts recognition model based on improved TTC algorithm," IEEE Access, vol. 7, pp. 134763-134771, 2019.

[11] C. Zhang, H. Zhang, X. Ma, M. Zhang, and S. Wang, "Driving risk assessment in work zones using cloud model," Mathematical Problems in Engineering, vol. 2018, Article ID 8759580, 9 pages, 2018.

[12] X. Gu, Q. Cai, J. Lee, Q. Xiang, Y. Ma, and X. Xu, "Proactive crash risk prediction modeling for merging assistance system at interchange merging areas," Traffic Injury Prevention, vol. 21, no. 3, pp. 234-240, 2020.

[13] V. Vignali, A. Bichicchi, A. Simone, C. Lantieri, G. Dondi, and M. Costa, "Road sign vision and driver behaviour in work zones," Transportation Research Part F: Traffic Psychology and Behaviour, vol. 60, pp. 474-484, 2019.
[14] R. T. Steinbakk, P. Ulleberg, F. Sagberg, and K. I. Fostervold, "Speed preferences in work zones: the combined effect of visible roadwork activity, personality traits, attitudes, risk perception and driving style," Transportation Research Part F: Traffic Psychology and Behaviour, vol. 62, pp. 390-405, 2019.

[15] X. X. Wei, X. Shu, B. S. Huang, E. L. Taylor, and H. Chen, "Analyzing traffic crash severity in work zones under different light conditions," Journal of Advanced Transportation, vol. 2017, Article ID 5783696, 10 pages, 2017.

[16] Y. Cheng, S. T. Parker, B. Ran, and D. A. Noyce, Integrating Crash, Real-Time Traffic, and Lane Closure Data for Statewide Highway Work Zone Safety Analysis, Transportation Research Board, Washington, DC, USA, 2015.

[17] M. Osman, R. Paleti, S. Mishra, and M. M. Golias, "Analysis of injury severity of large truck crashes in work zones," Accident Analysis \& Prevention, vol. 97, pp. 261-273, 2016.

[18] J. Daniel, K. Dixon, and D. Jared, "Analysis of fatal crashes in Georgia work zones," Transportation Research Record: Journal of the Transportation Research Board, vol. 1715, no. 1, pp. 18-23, 2000.

[19] N. J. Garber and M. Zhao, "Distribution and characteristics of crashes at different work zone locations in Virginia," Transportation Research Record, vol. 1794, no. 1, pp. 19-25, 2002.

[20] Y. Li and Y. Bai, "Comparison of characteristics between fatal and injury accidents in the highway construction zones," Safety Science, vol. 46, no. 4, pp. 646-660, 2008.

[21] M. Osman, R. Paleti, and S. Mishra, "Analysis of passengercar crash injury severity in different work zone configurations," Accident Analysis \& Prevention, vol. 111, pp. 161-172, 2018.

[22] R. Harb, E. Radwan, X. Yan, A. Pande, and M. Abdel-Aty, "Freeway work-zone crash analysis and risk identification using multiple and conditional logistic regression," Journal of Transportation Engineering, vol. 134, no. 5, pp. 203-214, 2008.

[23] A. J. Khattak, A. J. Khattak, and F. M. Council, "Effects of work zone presence on injury and non-injury crashes," Accident Analysis \& Prevention, vol. 34, no. 1, pp. 19-29, 2002.

[24] D. Sun, Y. Ai, Y. Sun et al., "A highway crash risk assessment method based on traffic safety state division," PLoS One, vol. 15, no. 1, Article ID e0227609, 2020.

[25] J. F. Morgan, A. R. Duley, and P. A. Hancock, "Driver responses to differing urban work zone configurations," Accident Analysis \& Prevention, vol. 42, no. 3, pp. 978-985, 2010.

[26] H. Ge and Y. Yang, "Research on calculation of warning zone length of freeway based on micro-simulation model," IEEE Access, vol. 8, pp. 76532-76540, 2020.

[27] H. Ge, M. Huang, Y. Lu et al., "Study on traffic conflict prediction model of closed lanes on the outside of expressway," Symmetry, vol. 12, no. 6, Article ID 928, 2020.

[28] X. Yang, Y. Lu, and Y. Lin, "Optimal variable speed limit control system for freeway work zone operations," Journal of Computing in Civil Engineering, vol. 31, no. 1, Article ID 04016044, 2017.

[29] Q. Meng, J. Weng, and X. Qu, "A probabilistic quantitative risk assessment model for the long-term work zone crashes," Accident Analysis \& Prevention, vol. 42, no. 6, pp. 1866-1877, 2010.

[30] X. Qu, S. Jin, and J. Weng, "Analysis of the relationship between aggregated traffic volume and traffic conflicts on expressways," Transportmetrica A: Transport Science, vol. 11, no. 7, pp. 648-658, 2015.

[31] Y. L. Pei and G. Z. Cheng, "Research on the relationship between discrete character of speed and traffic accident and 
speed management of freeway," China Journal of Expressway and Transport, vol. 17, no. 1, pp. 78-82, 2004.

[32] W. Genders and S. N. Razavi, "Impact of connected vehicle on work zone network safety through dynamic route guidance," Journal of Computing in Civil Engineering, vol. 30, no. 2, Article ID 4015020, 2016.

[33] A. P. Tarko, "Use of crash surrogates and exceedance statistics to estimate road safety," Accident Analysis \& Prevention, vol. 45, pp. 230-240, 2012.

[34] R. Fan, W. Wang, P. Liu, and H. Yu, "Using VISSIM simulation model and Surrogate Safety Assessment Model for estimating field measured traffic conflicts at freeway merge areas," IET Intelligent Transport Systems, vol. 7, no. 1, pp. 68-77, 2013.

[35] T. Schnell, J. S. Mohror, and F. Aktan, "Evaluation of traffic flow analysis tools applied to work zones based on flow data collected in the field," Transportation Research Record: Journal of the Transportation Research Board, vol. 1811, no. 1, pp. 57-66, 2002.

[36] R. Yu, M. Quddus, X. Wang, and K. Yang, "Impact of data aggregation approaches on the relationships between operating speed and traffic safety," Accident Analysis \& Prevention, vol. 120, pp. 304-310, 2018.

[37] Y. H. Wu and Z. P. Wu, "A safety analysis method for highway based on average speed and speed standard deviation," Journal of Highway and Transportation Research and Development, vol. 25, no. 3, pp. 139-142, 2008.

[38] H. P. Wang, D. Y. Qu, W. S. Yang et al., "Study on the relationship between speed discrete and accident rate based on the vehicle type proportion," Journal of Qingdao Technological University, vol. 34, no. 3, pp. 86-90, 2013.

[39] W. Shi, Y. Wei, and X. Li, "A safety distance design model based on just noticeable difference," Journal of Transportation Systems Engineering and Information Technology, vol. 11, no. 2, pp. 33-38, 2011.

[40] S. Siuhi and M. S. Kaseko, Parametric Study of StimulusResponse Behavior for Car-Following Models, Transportation Research Board, Washington, DC, USA, 2010.

[41] P. Liu, X. Qu, H. Yu, W. Wang, and B. Cao, "Development of a VISSIM simulation model for U-turns at unsignalized intersections," Journal of Transportation Engineering, vol. 138, no. 11, pp. 1333-1339, 2012.

[42] S. Ishak, Y. Qi, and P. Rayaprolu, "Safety evaluation of joint and conventional lane merge configurations for freeway work zones," Traffic Injury Prevention, vol. 13, no. 2, pp. 199-208, 2012.

[43] S. Zhang, Y. Xing, J. Lu et al., "Exploring the influence of truck proportion on freeway traffic safety using adaptive networkbased fuzzy inference system," Journal of Advanced Transportation, vol. 2019, Article ID 3879385, 13 pages, 2019.

[44] J. Maroto, E. Delso, J. Felez, and J. M. Cabanellas, "Real-time traffic simulation with a microscopic model," IEEE Transactions on Intelligent Transportation Systems, vol. 7, no. 4, pp. 513-527, 2006.

[45] F. Chen, J. Wang, Y. Deng et al., "Road safety risk evaluation by means of improved entropy TOPSIS-RSR," Safety Science, vol. 79, pp. 39-54, 2015. 